\title{
The Effect of High-Intensity Focused Ultrasound Rays in the Treatment of Uterine Fibroids on Tissue Parameters of Endometrial Receptivity
}

\author{
OA Melkozerova*, ID Shchedrina, GB Malgina, NV Bashmakova, GN Chistyakova, AA Grishkina and PB \\ Tsyvian
}

Ural Science Research Institute of Maternity and Child Care of the Ministry of Health of the Russian Federation, Russia

*Corresponding author: Oxana Alexandrovna Melkozerova, MD, assistant professor, Deputy Director of the Ural Science Research Institute of Maternity and Child Care of the Ministry of Health of the Russian Federation, Ekaterinburg, Russia.
Received Date: June 17, 2020

Published Date: June 24, 2020

\section{Abstract}

Objective: To analyse the effect of the ultrasonic energy during MRI-guided high-intensity focused ultrasound ablation (HIFU) of uterine fibroids on molecular markers of endometrial receptivity in women of reproductive age.

Study design: A prospective comparative cohort study of 60 women of reproductive age was conducted. The main group consisted of 32 patients suffering from the symptomatic course of uterine fibroids who received treatment with HIFU ablation of uterine fibroids: 17 women with node localization at the front wall of the uterus and the reflected action of ultrasonic waves on the endometrium and 15 women with the back wall node localization and penetrating effect of the waves. The control group consisted of 28 healthy fertile women examined voluntarily. The endometrium obtained with pipelle-biopsia on days 20-22 of the cycle was examined by immunohistochemistry before and three months after the treatment. The results were processed by the method of variation statistics using the SPSS 22.0.

Results: A significant decrease in the stromal expression of CD95 ${ }^{\text {bright }}$ in the endometrium to the level comparable with control values was observed after HIFU ablation of uterine fibroids (from $70.22 \pm 9.77 \mathrm{c} / \mathrm{s}$ to $48.81 \pm 5.47 \mathrm{c} / \mathrm{s} ; \mathrm{p}<0.001$; the control level $-47.80 \pm 2.13 \mathrm{c} / \mathrm{s}$ ). The ratio and expression of steroid receptors, proliferation markers, p53-dependent apoptosis and itsblockers, regulators and markers of angiogenesis, LIF and LIF-R signalling molecules in thestroma and endometrial glands did not change significantly after treatment ( $p>0.05$ in treatment dynamics).

It was demonstrated that focused ultrasound causes an increase in the level of expression of estradiol alpha receptors in the endometrial glands (118.07 \pm 14.01 points vs. $153.33 \pm 11.43$ points; $\mathrm{p}=0.02)$ and a decrease in stromal $\mathrm{p}^{53}$ expression $(30.80 \pm 21.61 \%$ vs.14.66 $\pm 3.74 \%$; $\mathrm{p}=0.007)$. No influence of the localization of fibroid node on the stromal expression of CD56 $6^{\text {bright+ }}$ was demonstrated. A significant increase in the stromal expression of CD34+ to the level statistically comparable with control values (from $26.00 \pm 1.63 \mathrm{c} / \mathrm{s}$ to $32.47 \pm 2.03 \mathrm{c} / \mathrm{s}$; $\mathrm{p}=0.011$; the control level $37.99 \pm 1.23 \mathrm{c} / \mathrm{s}$ ) was associated with ultrasound action.

Conclusion: This study did not reveal any significant negative effects of HIFU ablation of uterine fibroids on endometrial receptivity in women of reproductive age.

Keywords: Uterine fibroids; Magnetic resonance imaging guided high-intensity focused ultrasound ablation; Endometrial receptivity

Abbreviations: MRg: Magnetic Resonance Imaging Guided; HIFU: High-Intensity Focused Ultrasound 


\section{Introduction}

Uterine fibroids are a clinically relevant problem due to their high incidence: about $25 \%$ of women older than 35 years have myomas and one-third of those patients have symptoms associated with fibroids [1-2]. A combination of uterine fibroids and infertility occurs in $1.2-2.4 \%$ of women, while the mechanisms of the influence of uterine fibroids on fertility today remain a subject of discussion [1-6].

The problem of choosing the therapeutic tactics of uterine fibroids in patients of reproductive age planning pregnancy is associated not only with a change in the functional state of the myometrium after treatment, but also with a corresponding change in the function of the endometrium, which plays a key role in the initiation of implantation and invasion of trophoblast $[6,7]$.

In the presence of indications, myomectomy with careful layer-by-layer closure of the node bed is the first-line treatment method for patients with uterine fibroids planning a pregnancy [1,2,810]. In this case, the risk of uterine rupture after laparoscopic myomectomy does not exceed $0.5-1 \%[11,12]$. At the same time, when planning pregnancy for women of late reproductive age that have a certain decrease in ovarian reserve, the question of recovery time after myomectomy sometimes acquires fundamental importance. In addition, a uterine scar after myomectomy can consider an indication for abdominal delivery during subsequent pregnancy, which may increase perinatal risks in some way. In addition, there are certain risks of pregnancy with a scar on the uterus $[2,12]$.

These circumstances dictate the feasibility of a thorough study of alternative methods of preparing patients with uterine fibroids for pregnancy. As an alternative, there are conservative regression methods for the treatment of uterine fibroids, including magnetic resonance imaging guided high- intensity focused ultrasound (HIFU), which allows accelerating pregravid preparation and to avoid surgical intervention with scar formation on the uterus $[13,14]$.

The mechanisms of the influence of focused ultrasound rays passing through the endometrium during the procedure of HIFU ablation on the indicators of its receptivity are not fully understood, the results of individual studies are very contradictory. In this regard, it seems very relevant to study the functional activity of the endometrium after treatment using HIFU ablation of uterine fibroids.

The aim of this study is to analyse the effect of MRg HIFU ablation of uterine fibroids on molecular markers of endometrial receptivity in women of reproductive age.

\section{Material and Methods}

A prospective comparative cohort study of 60 women of reproductive age was conducted. The main group consisted of 32 patients suffering from the symptomatic course of uterine fibroids who re- ceived treatment with HIFU ablation of uterine fibroids. The control group consisted of 28 healthy fertile women who were examined on a voluntary basis, and who did not have a history of miscarriage and had a history of normal vaginal delivery after the physiological pregnancy. Depending on the predominant localization of the uterine fibroids, the patients were divided into two subgroups: A - 17 women with localization of the dominant node at the front wall of the uterus (in this case the endometrium was impacted by reflected ultrasonic waves); B - 15 women with localization of the fibroids at the posterior wall of the uterus and direct impact of ultrasound energy upon the endometrium.

The procedure of HIFU ablation was performed on the ExAblate-2000 (InSightec, Israel), combined into a single system with a 1.5 Tesla magnetic resonance imager (General Electric, USA). MR images were used for treatment localization, feedback control (beam guidance), real- time temperature mapping with the proton resonance frequency shift (PRFS) thermometry method, and post treatment verification of the ablated tissue.

The endometrial study was performed using the pipelle-biopsia method for $\mathrm{LG7}^{+}$day, determined by the urinary test for ovulation, as the period of the alleged "implantation window" in both case groups.

For the Immunohistochemical study, a two-stage streptavidin-biotin-peroxidase method was used with antigen unmasking using standard sets of monoclonal and polyclonal antibodies from Bond RTU Primary, USA and DAKO, Denmark. Using the DakoCytomation imaging system, a Reaction was performed. The Super Sensitive Polymer-HPR Detection System (BioGenex, USA) bezbiotin- free detection system was used to visualize primary antibodies.

For Immunohistochemical studies used serial paraffin sections. For Immunohistochemical reactions, paraffin sections were processed according to the traditional method using murine monoclonal antibodies to estrogen receptors- $\alpha$, progesterone receptors.

To analyse the results the H-score method of histological counting was used. To assess the expression of Ki-67, bcl-2, $\mathrm{p}^{53}$ antigens in the glands and stroma, proliferation and apoptosis indices were calculated - the ratio of the number of stained cell nuclei to the total number of nuclei in percent when counting at least 400 nuclei. Expression of CD56 $6^{\text {bright+ }}$ was evaluated by counting positive cells in the field of view at an increase of 400 when counting at least 10 fields of view. The expression of CD34+, VEGF-A and VEGFR-1 was determined in the epithelium, stroma of the endometrium and vascular endothelium. Activity was manifested in the form of staining of the membrane and cytoplasm of epithelial and endothelial cells. The expression of LIF, LIFR was determined on the cell membranes of the surface epithelium of the endometrial glands by counting the number of stained cells in the field of view at an increase of 400 , while not less than 10 fields of view were studied. 


\section{Theory/Calculation}

The inclusion criteria for the study of main group were as follows: women in reproductive age (18-45 years) with symptomatic uterine fibroids (pain, infertility, dysfunction of the pelvic organs); II-V types of nodes according to the FIGO classification (2011); sizes of nodes from 4 to $9 \mathrm{~cm}$; ovulatory cycle; informed voluntary consent to participate in the study signed by the patient. Criteria for not inclusion in the study: hyperplastic processes of the endometrium in combination with uterine myoma; the acute inflammatory process of the genitals; oncological diseases; severe extragenital pathology; pregnancy; taking hormone therapy less than 3 months before inclusion in the study; contraindications for the use of HIFU ablation.

Exclusion criteria from the study: the onset of pregnancy; severe complications during the treatment of fibroids; malignant and atypical changes according to histological examination of endometrium; refusal of the patient from further participation in the study. Statistical analysis of the results was carried out using SPSS 16.0, SPSS: IBM Company (USA) and Statistical 10.0, StatSoft (USA). Statistical data were specified as the mean \pm standard deviation. Significance tests were performed according to normal distribution testing via t-test for independent and paired samples and Mann-Whitney-U and Wilcoxon testing for not normally distributed variables with a significance level of $\mathrm{p}<0.05$. The required sample size was calculated using sealed envelope ${ }^{\circledR}$. UK when taking an alpha level of 0.05 and a confidence level of $95 \%$ with a dropout of $10 \%$.

\section{Results}

The average age of the patients did not significantly differ and amounted to $37.50 \pm 1.33$ years in the main group and $35.85 \pm 1.43$ years in the control group ( $p>0.05)$. Patients did not have significant differences in anthropometric indices; average growth and weight parameters were observed. BMI in the main group was $24.64 \pm 3.06$ $\mathrm{kg} / \mathrm{cm}^{2}$, in the control group $23.04 \pm 1.86 \mathrm{~kg} / \mathrm{cm}^{2} ; \mathrm{p}>0.05$. The main clinical manifestations of the disease in patients of the main group were menometrorrhagia (40.63\%) and pain (53.13\%). The frequency of infertility as a clinical manifestation of uterine fibroids was $37.5 \%$, wherein primary infertility among women of the main group accounted for $15.63 \%$, secondary infertility - for $21.87 \%$ of women with uterine fibroids.

A dynamic analysis of the uterine fibroids clinical manifestations after treatment with HIFU ablation showed a significant decrease in the incidence of pain from $53.13 \%$ to $15.63 \%$; $p=0.002$ and menorrhagia from $40.63 \%$ to $12.50 \%$; $p=0.002$. Significant differences in the frequency of algodismenorea, dyspareunia and leucorrhoea were not detected. We studied samples obtained by pipelle-biopsia method on $\mathrm{LG7}^{+}$day of the menstrual cycle to assess the effect of the energy of focused ultrasonic waves during HIFU ablation of uterine fibroids on functional activity and endometrial receptivity.

A comparative analysis of the sex steroid receptors expression and their ratio in the endometrium in the dynamics of treatment using HIFU ablation of uterine fibroids revealed no significant differences (Table 1, Figures 1A\&1B).

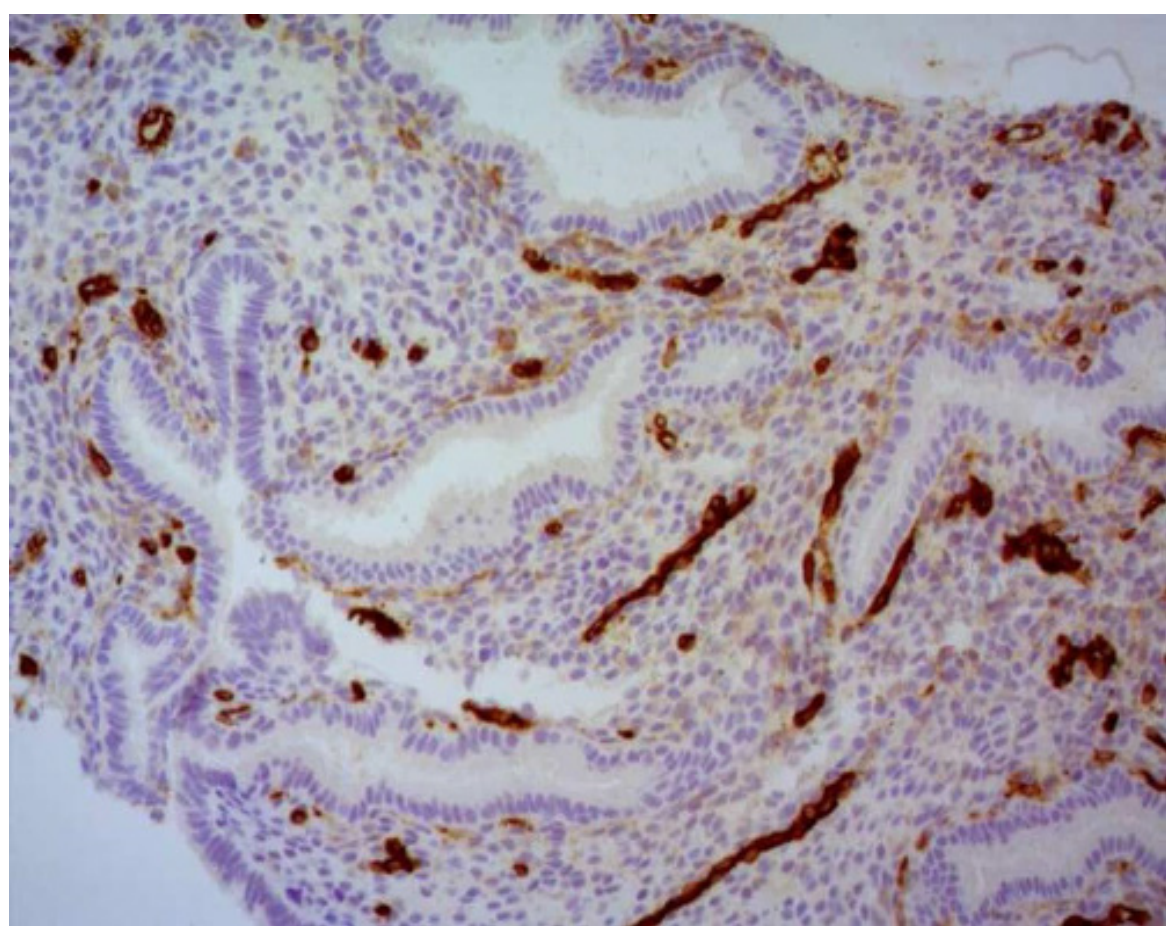

Figure 1A: Low expression of estradiol alpha receptors in the stroma of the implantation endometrium (LG7+) in women with uterine fibroids before FUS-MRI. Immunohistochemical study. Magnification x 400 . 


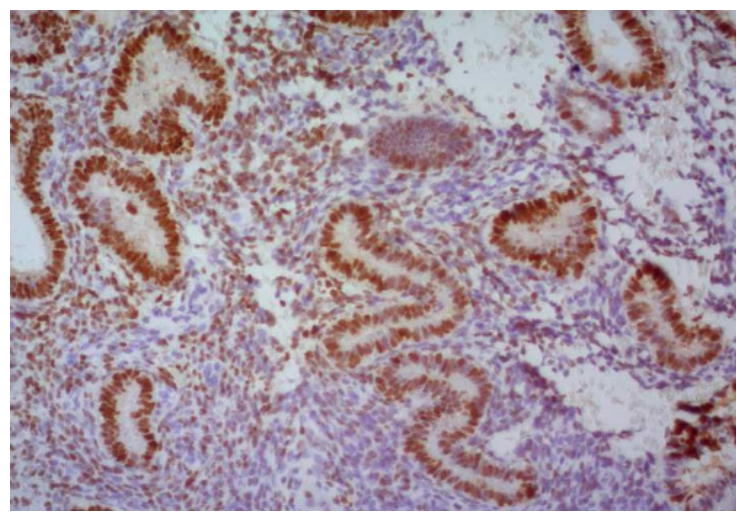

Figure 1B: High expression of estradiol alpha receptors in the glands of the implantation endometrium (LG7 ${ }^{+}$) after FUS-MRI ablation of uterine fibroids. Immunohistochemical study. Magnification x 400.

Table 1: The endometrial indicators dynamics after HIFU ablation of uterine fibroids ( $L G 7^{+}$day of cycle; $M \pm m, p$ ).

\begin{tabular}{|c|c|c|c|c|}
\hline \multirow[t]{2}{*}{ Parameters } & $\begin{array}{l}\text { Women with uterine fibroids } \\
\text { before treatment }(n=32)\end{array}$ & $\begin{array}{l}\text { After treatment using HIFU abla- } \\
\text { tion of uterine fibroids }(n=32)\end{array}$ & $\begin{array}{l}\text { Control group } \\
(\mathrm{n}=\mathbf{2 8})\end{array}$ & \multirow[t]{2}{*}{ p-value } \\
\hline & 1 & 2 & 3 & \\
\hline${ }^{1} \mathrm{ER}$ in the stroma & $71.26 \pm 10.55$ & $84.78 \pm 7.60$ & $95.56 \pm 15.30$ & NS \\
\hline${ }^{1} \mathrm{PR}$ in the stroma & $248.48 \pm 11.48$ & $241.81 \pm 8.94$ & $263.47 \pm 17.15$ & NS \\
\hline${ }^{1} \mathrm{ER}$ in the glands & $133.67 \pm 12.34$ & $157.89 \pm 11.49$ & $198.49 \pm 18.69$ & $\mathrm{p} 1-3=0.001$ \\
\hline${ }^{1} \mathrm{PR}$ in the glands & $185.56 \pm 21.91$ & $222.48 \pm 19.35$ & $231.21 \pm 24.44$ & NS \\
\hline PR/ER in the stroma & $2.97 \pm 1.07$ & $2.85 \pm 1.18$ & $2.76 \pm 0.06$ & NS \\
\hline PR/ ER in the glands & $1.61 \pm 1.4$ & $1.40 \pm 1.68$ & $1.16 \pm 0.29$ & NS \\
\hline${ }^{2} \mathrm{CD} 56^{\text {brightt }}$ in the stroma & $70.22 \pm 9.77$ & $48.81 \pm 5.47$ & $47.8 \pm 2.13$ & p1-3<0.001 p1-2<0.001 \\
\hline${ }^{2} \mathrm{CD} 56^{\text {bright }}$ in the glands & $13.33 \pm 3.50$ & $15.33 \pm 4.84$ & $14.56 \pm 2.14$ & NS \\
\hline${ }^{2} \mathrm{LIF}$ in the glands & $139.23 \pm 30.69$ & $208.3 \pm 31.47$ & $202.22 \pm 10.19$ & $\mathrm{p} 1-2=0.02 \mathrm{p} 1-3=0.02$ \\
\hline${ }^{2} \mathrm{LIF}$ in the stroma & $40.02 \pm 13.62$ & $171.92 \pm 42.71$ & $153.46 \pm 9.14$ & $\mathrm{p} 1-2=0.002 \mathrm{p} 1-3=0.003$ \\
\hline${ }^{2}$ LIFR in the glands & $121.04 \pm 19.47$ & $113.85 \pm 24.23$ & $165.54 \pm 23.14$ & NS \\
\hline${ }^{2} \mathrm{LIFR}$ in the stroma & $69.08 \pm 11.38$ & $74.08 \pm 21.33$ & $85.54 \pm 19.30$ & NS \\
\hline${ }^{3} \mathrm{Ki} 67$ in the stroma & $19.074 \pm 2.205$ & $19.63 \pm 2.25$ & $24.00 \pm 5.08$ & NS \\
\hline${ }^{3} \mathrm{Ki} 67$ in the glands & $29.37 \pm 3.72$ & $24.81 \pm 3.83$ & $25.00 \pm 9.06$ & NS \\
\hline${ }^{3}$ p 53 in the stroma & $35.037 \pm 4.24$ & $26.81 \pm 4.63$ & $81.81 \pm 7.68$ & $\mathrm{p} 1-3<0.001 \mathrm{p} 2-3<0.001$ \\
\hline${ }^{3}$ p 53 in the glands & $24.40 \pm 3.45$ & $32.407 \pm 5.46$ & $93.83 \pm 1.23$ & $\mathrm{p} 1-3<0.001 \mathrm{p} 2-3<0.001$ \\
\hline $3 \mathrm{bcl} 2$ in the stroma & $50.037 \pm 9.704$ & $48.630 \pm 8.39$ & $12.25 \pm 3.59$ & $\mathrm{p} 1-3<0.001 \mathrm{p} 2-3<0.001$ \\
\hline${ }^{3} \mathrm{bcl} 2$ in the glands & $139.77 \pm 17.101$ & $161.667 \pm 24.05$ & $23.00 \pm 3.07$ & p1-3<0.001 p2-3<0.001 \\
\hline${ }^{2} \mathrm{CD} 34^{+}$in the stroma & $57.33 \pm 1.48$ & $57.667 \pm 1.438$ & $37.99 \pm 1.23$ & p1-3<0.001 p2-3<0.001 \\
\hline TEGF-A in the stroma & $253.41 \pm 20.88$ & $239.44 \pm 15.721$ & $206.67 \pm 10.38$ & $\mathrm{p} 1-3=0.017 \mathrm{p} 2-3=0.042$ \\
\hline${ }^{1}$ VEGF-R1 in the stroma & $43.44 \pm 4.44$ & $49.14 \pm 7.21$ & $78.28 \pm 14.64$ & $\mathrm{p} 1-3=0.026 \mathrm{p} 2-3=0.042$ \\
\hline $\begin{array}{l}\text { VEGF-A/VEGF-R1 in the } \\
\text { stroma }\end{array}$ & $5.802 \pm 0.85$ & $4.87 \pm 0.57$ & $2.77 \pm 0.71$ & $\mathrm{p} 1-3=0.007 \mathrm{p} 2-3=0.031$ \\
\hline
\end{tabular}

Note: ${ }^{1-}$ points $\mathrm{H}$-score; ${ }^{2-}$ cells in the field of view; ${ }^{3-} \%$ stained cells

After treatment with HIFU ablation, a statistically significant decrease in the stromal expression of $\mathrm{CD}_{5} 6_{\text {bright+ }}$ was observed in patients with uterine fibroids, to a level comparable with control values (Table 1). There were no significant differences in the level of $\mathrm{CD} 56^{\text {bright+ }}$ expression in the endometrial glands in the observation groups (Table 1, Figure 2A\&2B).
There was a significant increase in the leukaemia inhibitory factor (LIF) stromal expression in the endometrial glands to a level statistically comparable with control values after HIFU ablation of uterine fibroids (Table 1). There were no significant changes in the expression of receptor for LIF after treatment. 


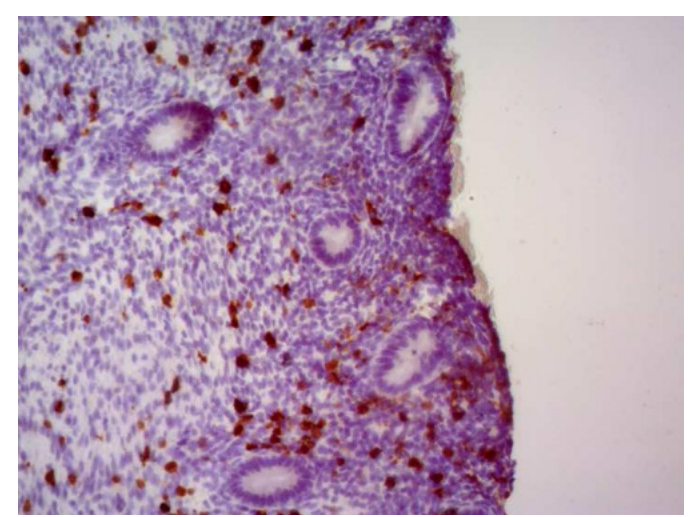

Figure 2A: High $C D^{56+b r i g h t}$ stromal expression in the endometrium $\left(L G 7^{+}\right)$in patients with uterine fibroids before FUS-MRI. Immunohistochemical study. Magnification x 400 .

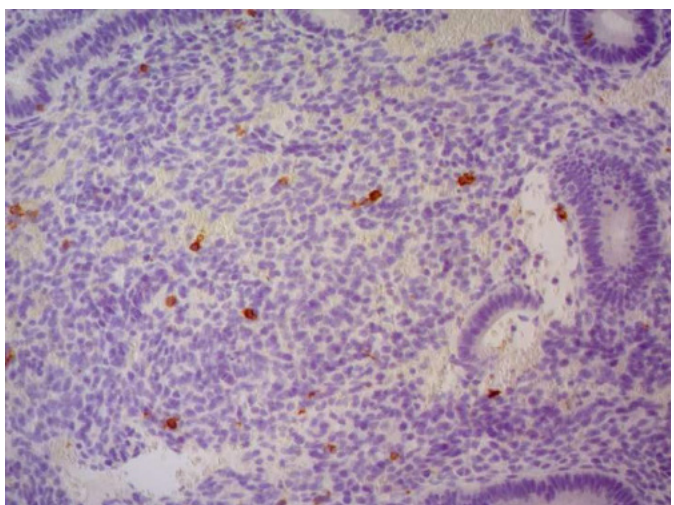

Figure 2B: Low $C D^{56+b r i g h t}$ stromal expression in patients with uterine fibroids after treatment. Immunohistochemical study. Magnification $\mathrm{x}$ 400.

The expression of proliferation markers, $\mathrm{p}^{53}$-dependent apoptosis and its blockers in the stroma and endometrial glands did not significantly change after therapy with HIFU (Table 1).
At the same time, it should be noted that $\mathrm{p}^{53}$ expression indices after HIFU fibroids ablation remained significantly lower and bcl-2 on the contrary, were significantly higher than control values (Table 1, Figures 3A\&3B, 4A\&4B).

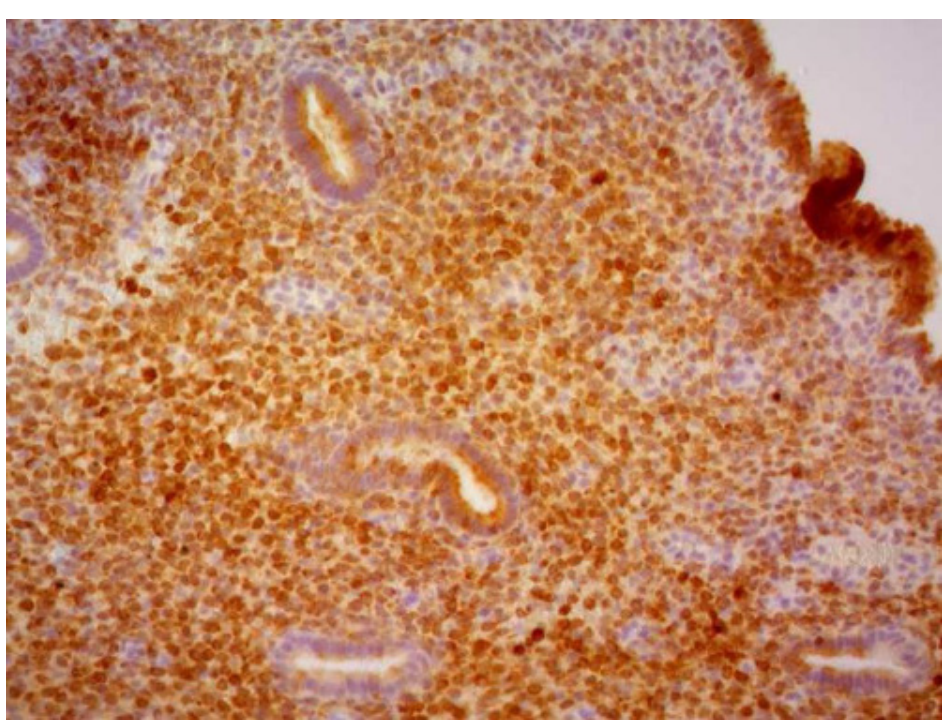

Figure 3A: High expression of the $\mathrm{p}^{53}$ in the glands of endometrium (LG7+) in women with uterine fibroids. Immunohistochemical study. Magnification x 400 . 


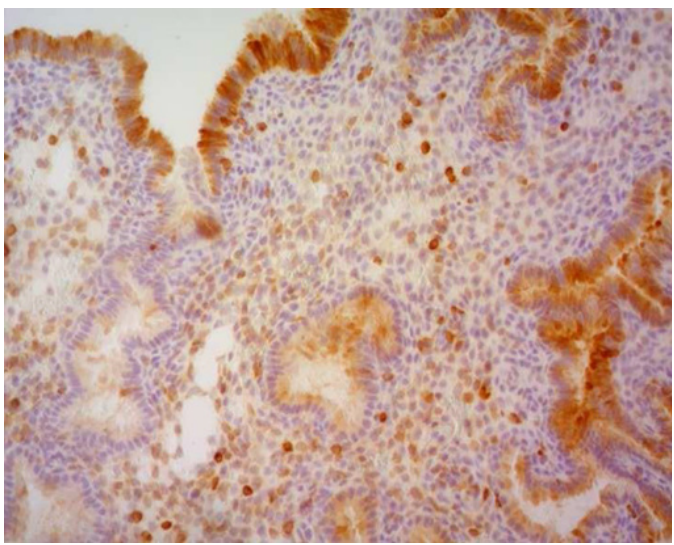

Figure 3B: Low expression of the p53 in endometrial stroma (LG7+) of healthy fertile women. Immunohistochemical study. Magnification $x$ 400.

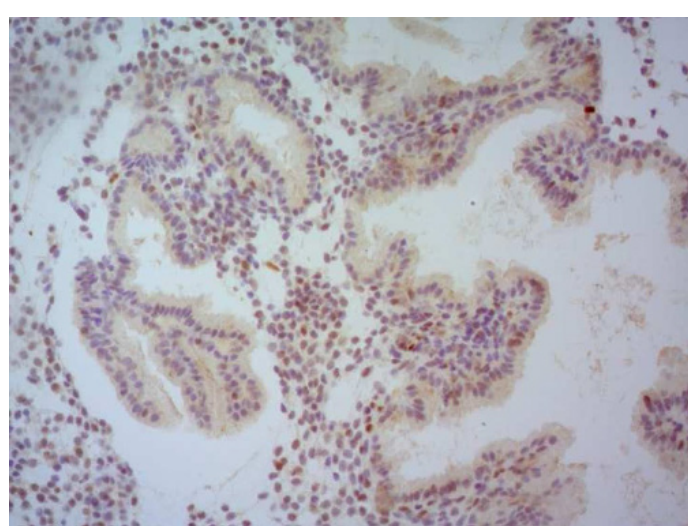

Figure 4A: High expression of the bcl-2 in the stroma of the implantation endometrium (LG7+) in patients with uterine fibroids. Immunohistochemical study. Magnification x 400 .

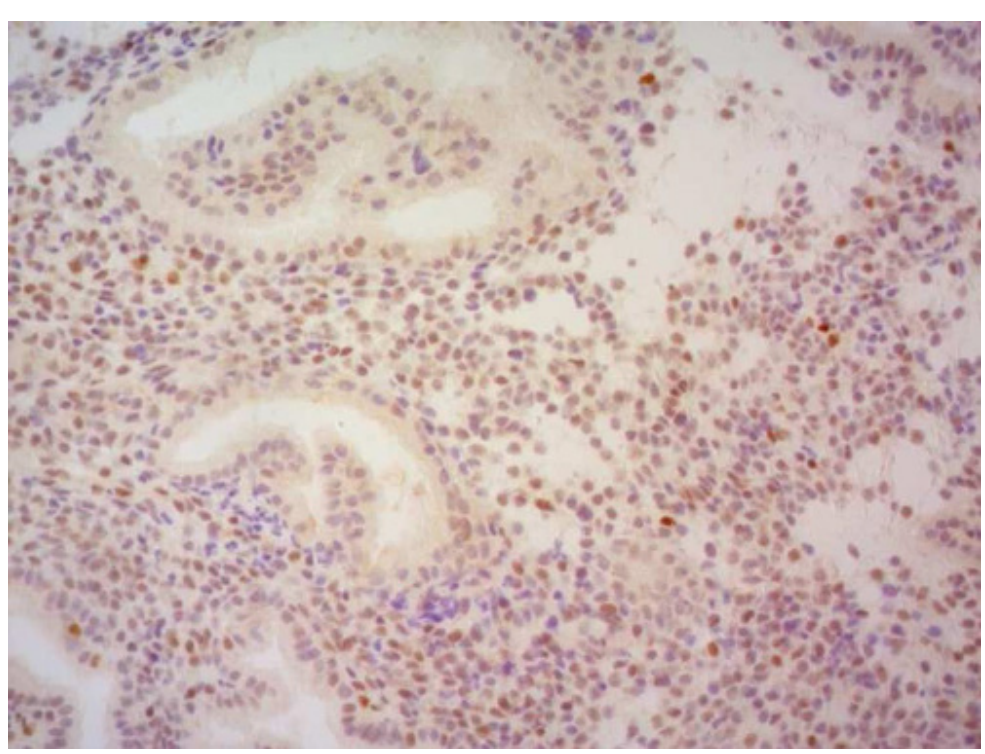

Figure 4B: Low stromal expression of the bcl-2 in implantation endometrium of healthy fertile women. Immunohistochemical study. Magnification $\times 400$

The level of stromal expression of CD34+ in patients after HIFU uterine fibroids ablation did not significantly change, remaining significantly higher than the control values throughout the observation period (Table 1, Figure 5A). 
There were no significant changes in the expression of the angiogenesis regulators vascular endothelial growth factor A (VEGF A) \& its receptor 1 (VEGF-R1) and their ratio VEGF- A/VEGF-R1 in endometrial samples after treatment. This ratio was significantly higher than the control values during the entire observation period, which demonstrates the pro-angiogenic potential of endometrial tissue in patients with uterine myoma (Table 1, Figure 5B).

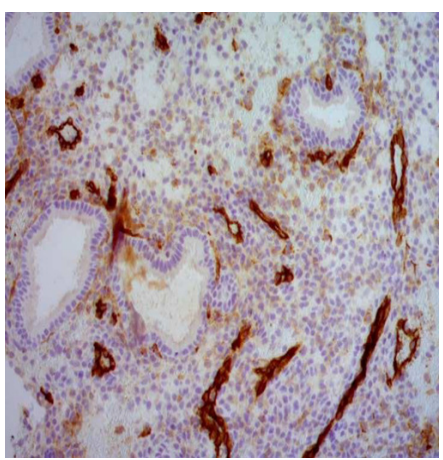

Figure 5A: Expressed expression of CD34+ in the stroma of the implantation endometrium (LG7+) in patients with uterine fibroids. Immunohistochemical study. Magnification x 400.

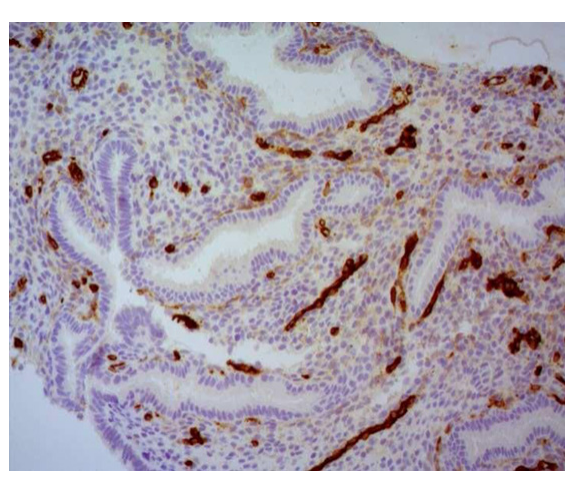

Figure 5B: Expressed expression of VEGF-A in the stroma of the implantation endometrium (LG7+) in patients with uterine fibroids. Immunohistochemical study. Magnification x 400 .

It was found that focused ultrasound rays passing through the endometrium cause an increase in the expression level of estradiol alpha recipes in the endometrial glands and a decrease in stromal expression $\mathrm{p} 53$. There were no significant differences in the level of stromal and glandular expression of the Ki67 proliferation marker and bcl-2 apoptosis regulator in female samples depending on the location of the dominant treated node (Table 2).

Table 2: The endometrial indicators depending on the direct or reflected exposure to ultrasonic waves during HIFU ablation of uterine fibroids (LG7 ${ }^{+}$ day of cycle; $M \pm m, p$ ).

\begin{tabular}{|c|c|c|c|c|c|c|}
\hline Parameters & $\begin{array}{c}\text { Uterine fibroids } \\
\text { on the front wall of } \\
\text { uterus before treat- } \\
\text { ment }(n=17)\end{array}$ & $\begin{array}{l}\text { Uterine fibroids } \\
\text { on the back wall } \\
\text { of uterus before } \\
\text { treatment }(n=15)\end{array}$ & $\begin{array}{l}\text { Uterine fibroids } \\
\text { on the front wall } \\
\text { of uterus after } \\
\text { treatment }(n=17)\end{array}$ & $\begin{array}{l}\text { Uterine fibroids } \\
\text { on the back wall of } \\
\text { uterus after treat- } \\
\text { ment }(n=15)\end{array}$ & $\begin{array}{l}\text { Control group } \\
\quad(n=28)\end{array}$ & \multirow[t]{2}{*}{ p-value } \\
\hline & 1 & 2 & 3 & 4 & 5 & \\
\hline${ }^{1} \mathrm{ER}$ in the stroma & $64.82 \pm 14.04$ & $78.33 \pm 13.72$ & $83.0 \pm 10.43$ & $89.27 \pm 5.66$ & $95.56 \pm 15.3$ & NS \\
\hline${ }^{1} \mathrm{PR}$ in the stroma & $243.24 \pm 15.43$ & $259.87 \pm 14.51$ & $245.88 \pm 11.63$ & $235.20 \pm 11.99$ & $263.47 \pm 17.15$ & NS \\
\hline${ }^{1} \mathrm{ER}$ in the glands & $139.12 \pm 16.56$ & $118.07 \pm 14.01$ & $155.29 \pm 17.26$ & $153.33 \pm 11.43$ & $198.49 \pm 18.69$ & ${ }^{* *} \mathrm{p} 2-4=0.002$ \\
\hline${ }^{1} \mathrm{PR}$ in the glands & $190.59 \pm 26.30$ & $167.00 \pm 34.39$ & $232.35 \pm 20.28$ & $217.33 \pm 33.28$ & $231.21 \pm 24.44$ & NS \\
\hline PR/ER in the stroma & $3.75 \pm 1.09$ & $3.31 \pm 1.06$ & $2.96 \pm 1.11$ & $2.63 \pm 2.12$ & $2.76 \pm 0.06$ & NS \\
\hline PR/ ER in the glands & $1.36 \pm 1.58$ & $1.414 \pm 2.45$ & $1.49 \pm 1.17$ & $1.42 \pm 2.91$ & $1.16 \pm 0.29$ & NS \\
\hline $\begin{array}{c}{ }^{2} \mathrm{CD} 56^{\text {bright+ }} \text { in the } \\
\text { stroma }\end{array}$ & $70.24 \pm 12.85$ & $66.93 \pm 12.86$ & $31.35 \pm 6.78$ & $20.07 \pm 6.82$ & $47.8 \pm 2.13$ & $\begin{array}{l}{ }^{* *} \mathrm{p} 1-3=0.020 \\
{ }^{* *} \mathrm{p} 2-4=0.001\end{array}$ \\
\hline${ }^{2} \mathrm{CD} 56^{\text {brightt }}$ in the glands & $11.76 \pm 0.70$ & $14.82 \pm 1.15$ & $14.82 \pm 1.15$ & $16.40 \pm 1.15$ & $14.56 \pm 2.14$ & NS \\
\hline
\end{tabular}




\begin{tabular}{|c|c|c|c|c|c|c|}
\hline${ }^{2} \mathrm{LIF}$ in the glands & $139.23 \pm 30.69$ & $113.85 \pm 18.47$ & $225.40 \pm 33.98$ & $206.0 \pm 39.46$ & $202.22 \pm 10.19$ & $\begin{array}{l}{ }^{* *} \mathrm{p} 1-3=0.02 \\
{ }^{* *} \mathrm{p} 2-4=0.01\end{array}$ \\
\hline${ }^{2} \mathrm{LIF}$ in the stroma & $40.02 \pm 13.62$ & $11.15 \pm 2.29$ & $133.50 \pm 29.53$ & $148.33 \pm 32.87$ & $153.46 \pm 9.14$ & $\begin{array}{l}* * \mathrm{p} 1-3=0.003 \\
{ }^{* *} \text { p1-3<0.001 }\end{array}$ \\
\hline${ }^{2}$ LIFR in the glands & $121.04 \pm 19.47$ & $107.69 \pm 16.92$ & $121.0 \pm 30.81$ & $111.0 \pm 30.85$ & $165.54 \pm 23.14$ & NS \\
\hline${ }^{2}$ LIFR in the stroma & $69.08 \pm 11.38$ & $48.46 \pm 11.89$ & $81.30 \pm 24.41$ & $70 \pm 13.88$ & $85.54 \pm 19.30$ & NS \\
\hline${ }^{3} \mathrm{Ki} 67$ in the stroma & $20.059 \pm 11.60$ & $18.800 \pm 12.208$ & $19.706 \pm 11.655$ & $14.33 \pm 5.30$ & $34.00 \pm 5.08$ & NS \\
\hline${ }^{3} \mathrm{Ki} 67$ in the glands & $32.64 \pm 27.62$ & $26.40 \pm 34.51$ & $26.82 \pm 21.35$ & $20.26 \pm 14.40$ & $75.00 \pm 19.06$ & NS \\
\hline${ }^{3}$ p 53 in the stroma & $36.47 \pm 22.28$ & $30.80 \pm 21.61$ & $32.52 \pm 26.37$ & $14.66 \pm 13.74$ & $81.81 \pm 7.68$ & ${ }^{* *}$ p $2-4=0.007$ \\
\hline${ }^{3} \mathrm{p} 53$ in the glands & $31.706 \pm 29.76$ & $22.93 \pm 22.98$ & $36.76 \pm 32.35$ & $24.00 \pm 18.14$ & $93.83 \pm 1.23$ & NS \\
\hline${ }^{3} \mathrm{bcl} 2$ in the stroma & $48.00 \pm 47.01$ & $55.60 \pm 56.45$ & $47.41 \pm 48.62$ & $54.26 \pm 33.22$ & $42.25 \pm 3.59$ & NS \\
\hline${ }^{3} \mathrm{bcl} 2$ in the glands & $123.88 \pm 81.46$ & $158.40 \pm 99.48$ & $174.41 \pm 118.39$ & $131.33 \pm 130.103$ & $123.00 \pm 3.07$ & NS \\
\hline${ }^{2} \mathrm{CD} 34+$ in the stroma & $27.176 \pm 1.461$ & $26.000 \pm 1.629$ & $27.533 \pm 2.713$ & $32.467 \pm 2.030$ & $37.99 \pm 1.23$ & $* *$ p2-4=0.011 \\
\hline${ }^{1}$ VEGF-A in the stroma & $93.706 \pm 26.540$ & $115.933 \pm 29.157$ & $75.647 \pm 19.439$ & $133.533 \pm 22.199$ & $206.67 \pm 10.38$ & $\begin{array}{l}* \text { p3-4 }=0.031 \\
{ }^{*} \text { p3-5 }=0.012\end{array}$ \\
\hline IVEGF-R1 in the stroma & $117.824 \pm 27.387$ & $160.000 \pm 36.253$ & $112.588 \pm 31.771$ & $182.200 \pm 38.567$ & $78.28 \pm 14.64$ & NS \\
\hline $\begin{array}{l}\text { VEGF-A/VEGF-R1 in } \\
\text { the stroma }\end{array}$ & $0.79 \pm 0.96$ & $0.72 \pm 0.80$ & $0.67 \pm 0.61$ & $0.73 \pm 0.57$ & $2.77 \pm 0.77$ & NS \\
\hline
\end{tabular}

Note: *Student-test for unrelated population,; ${ }^{* *}$ paired Student t-test; ${ }^{1-}$ points $\mathrm{H}$-score; ${ }^{2-}$ cells in the field of view; ${ }^{3-} \%$ stained cell

High levels of $\mathrm{CD}_{5} 6_{\text {bright+ }}$ stromal expression were noted before treatment regardless of the node localization. A significant decrease in the $\mathrm{CD}_{56_{\text {bright }}}$ stromal expression was determined after HIFU ablation of uterine fibroids in both groups. Thus, no dependence of the $\mathrm{CD} 56^{\text {bright+ }}$ stromal expression on the localization of the treated by HIFU node was revealed (Table 2).

A significant increase in the stromal expression of $\mathrm{CD}_{34}{ }^{+}$in the endometrium was noted to a level statistically comparable with the control values after the passage of ultrasonic waves through the endometrium (Table 2, Figure 5).

\section{Discussion}

The high prevalence of uterine fibroids in late reproductive age women planning a pregnancy dictates the need for meaningful preparation to pregnancy aimed at reducing the tumour[1-6]. According to many authors, laparoscopic myomectomy is an effective operation for women who are planning a pregnancy with subsequent good reproductive results regarding pregnancy outcomes and the frequency of miscarriages [8-10]. On the other hand, there are a number of features of the course of pregnancy in the presence of a scar on the uterus after myomectomy. The main factor in gestation after myomectomy is the functional and morphological condition of the scar $[11,12]$.

Another aspect of the problem is the length of the recovery period after surgical treatment of the uterus, which is of great importance when planning pregnancy in late reproductive age, when a decrease in ovarian reserve becomes apparent. Some patients have contraindications to surgical treatment, or refuse to carry it out for various reasons.
In this clinical situation, as an alternative method of treating uterine fibroids with a clear account of the indications and conditions described by many authors $[2,13,14]$, the method of HIFU Ablation can be used.

The study of the effect of focused ultrasound energy on the expression of signalling molecules depending on the direct or indirect reflected effects of sound waves on endometrial tissue is especially relevant.

According to some researchers, one of the key mechanisms of synchronized expression of endometrial receptivity factors is the interaction of sex steroid hormones with endometrial receptors $[7,15]$. Our data indicate the absence of the influence of ultrasonic waves during HIFU ablation on the expression level and the ratio of steroid receptors in the stroma and endometrial glands during the period of the proposed "implantation window".

Studying the molecular mechanisms of uterine bleeding associated with uterine myoma, the researchers used genome sequencing to determine gene expression profiles in patients with symptomatic uterine myoma [16,17]. Statistical analysis revealed 245 genes predominantly associated with immuno-inflammatory genes, many of which regulate the synthesis of IL-15, which plays a key role in the development and functioning of natural uterine killers (uNK) [16-18]. Having studied the distribution of CD56+bright in the endometrium, scientists found a significant increase in their stromal expression in the presence of menometrorrhagia [19-20].

An increase in the level of CD56 ${ }_{\text {+bright }}$ cells in the endometrium in combination with activation of pathological neoangiogenesis can increase the amount of bleeding in women with uterine myoma, 
which we observed in our study. Initially, prior to treatment, most patients with uterine myoma showed high expression of CD56 ${ }_{\text {+bright' }}$ $\mathrm{CD}^{+} 4^{+}$and angiogenesis inducers (VEGF-A) in the endometrial stroma compared with fertile healthy women.

Moreover, the ratio of regulators of neoangiogenesis VEGF-A/ VEGFR1 testified to a pronounced initial pro-angiogenic potential of endometrial tissue. Under the influence of focused ultrasonic waves, a statistically significant decrease in the stromal expression of natural uterine killers was observed to a level comparable to that in healthy fertile women.

After HIFU, the expression of angiogenesis markers CD34+ and VEGF-A in the stroma of the endometrium did not statistically significantly change, remaining at a high level. This explains the incomplete regression of complaints of menorrhagia in some patients after treatment using HIFU ablation.

In addition, in patients with uterine myoma, our study revealed low expression of the $\mathrm{p}^{53}$ apoptosis marker and, accordingly, a high level of bcl-2 apoptosis blocker in the stroma and endometrial glands, which did not change significantly after treatment, remaining statistically significantly different from the control.

The implantation process is always accompanied by activation of $\mathrm{p}^{53}$-dependent apoptosis in the glands, stroma, and surface epithelium and in the vessels of the endometrium [21,22]. Activation of $\mathrm{p}^{53}$-dependent apoptosis occurs due to inhibition of the synthesis of the apoptosis blocker bcl-2, regulated by C-Jun proteins [22]. The biological meaning of this phenomenon during implantation is associated with the mobilization of endometrial cells for normal blastocyst nidation and trophoblast invasion into the stroma and spiral uterine arteries.

At the same time, in our study, after the treatment of uterine fibroids with HIFU ablation, there was a statistically significant increase in the level of stromal and glandular expression of LIF receptor signalling molecules, which play a key role in the successful interaction of the blastocyst with endometrium and the adhesion of the latter on its surface.

Identified changes can be of great clinical significance. In previous studies [23], we showed that HIFU ablation of uterine fibroids can be an effective procedure for preparing for pregnancy with the right choice of conditions and indications for its use.

\section{Conclusion}

The study did not reveal any significant changes in the functional state of the endometrium after HIFU ablation of uterine fibroids. The positive aspects of the influence of HIFU energy include the decrease in the excess stromal expression of uNK and an increase in glandular and stromal LIF expression in the endometrium. The HIFU ablation can be considered as the second line of treatment of uterine fibroids in women who planning pregnancy in case of the right choice of indications and conditions.

\section{Highlights}

- The ratio and expression of steroid receptors, proliferation markers, $\mathrm{p}^{53}$-dependent apoptosis and its blockers, regulators and markers of angiogenesis, LIF and LIF-R signalling molecules in the stroma and endometrial glands did not change significantly after HIFU ablation of uterine fibroids.

- A significant decrease in the stromal expression of uterine nature killer cells was observed after HIFU ablation of uterine fibroids.

- A significant increase of the endothelial cells expression in stroma of endometrium was associated with ultrasound action.

\section{Acknowledgement}

The study was supported by grant 19-315-90028 of the Russian Foundation for BasicResearch (RFBR) as part of a competition for the best fundamental research projects carried out by young scientists studying in graduate school.

\section{Conflict of Interest}

Authors declare no conflict of interest.

\section{References}

1. Giuliani E, As-Sanie S, Marsh EE (2020) Epidemiology and management of uterine fibroids. International Journal of Gynecology and Obstetrics 148 (1): 3-9.

2. Adamyan LV, Andreeva EN, Artymchuk NV, et al. (2015) Uterine fibroids, diagnosis, treatment, recommendations. Moscow: Clinical recommendations, treatment protocol.

3. Vlahos NF, Theodoridis TD, Partsinevelos GA (2017) Myomas and adenomyosis: Impact on Reproductive Outcome. Biomed Res Int 2017: 5926470 .

4. Parazzini F, Tozzi L, Bianchi S (2016) Pregnancy outcome and uterine fibroids. Best Pract Res Clin Obstet Gynaecol 34: 74-84.

5. Kuznetsova IV, Evsyukova LV (2016) Uterine fibroids and fertility. Gynecology 18(3): 23-29.

6. Dzhemlikhanova L Kh, Niauri DA, Abdulkadyrova ZK (2016) Uterine fibroids and the effectiveness of assisted reproductive technology programs. Journal of Obstetrics and Women's Diseases 65(6): 79-87.

7. Carp HJA (2017) Recurrent Pregnancy Loss: Causes, Controversies, and Treatment. ( $2^{\text {nd }}$ edn) NY: CRS Press, Taylor \& Francis Group, USA.

8. Donnez J, Dolmans MM (2016) Uterine fibroid management: from the present to the future. Hum Reprod Update 22(6): 665-686.

9. Wang Y, Zhang S, Li C, Li B, Ouyang L (2020) Minimally invasive surgery for uterine fibroids. Ginekol Pol 91(3): 149-157.

10. Metwally M, Raybould G, Cheong YC, Horne AW (2012) Surgical treatment of fibroids for subfertility. Cochrane Database Syst Rev 29(1): CD003857.

11.Zaami S, Montanari Vergallo G, Malvasi A, Marinelli E (2019) Uterine rupture during induced labor after myomectomy and risk of lawsuits. Eur Rev Med Pharmacol Sci 23(4): 1379- 1381.

12. Kundu S, Iwanuk C, Staboulidou I, Garcia-Rocha GJ, Soergel P, et al. (2018) Morbidity, fertility and pregnancy outcomes after myoma enucleation by laparoscopy versus laparotomy. Arch Gynecol Obstet 297(4): 969- 976. 
13. Fan HJ, Zhang C, Lei HT, Cun JP, Zhao W, et al. (2019) Ultrasound-guided high-intensity focused ultrasound in the treatment of uterine fibroids. Medicine 98(10): 1-6.

14. Nazarenko GI, Krasnova TV, Tonkogorova IV, Bogdanova EG, Prilutskaya MA (2016) Assessment of Efficacy and Safety of HIFU-ablation in Uterine Myoma Treatment Considering Nodes Localization. Ultrasound and functional diagnostics 1: 29-39

15. Toprak M, Ates O, Ozsoy AZ, Bozkurt N, Sondas SS, et al. (2019) Analysis of estrogen and progesterone receptor gene polymorphisms in leiomyoma. J Clin Lab Anal 33(3): e22704.

16. Liu X, Liu Y, Zhao J, Liu J (2018) Screening of potential biomarkers in uterine leiomyomas disease via gene expression profiling analysis. Molecular Mol Med Rep 17(5): 6985-6996.

17. Cao T, Jiang Y, Wang Z, Zhang N, Al-Hendy A, et al. (2019) H19 lncRNA identified as a master regulator of genes that drive uterine leiomyomas. Oncogene 38(27): 5356-5366.

18. Chodankar R, Critchley HOD (2019) Biomarkers in abnormal uterine bleeding. Biol Reprod 101(6): 1155-66.
19. Moffett A, Colucci F (2014) Uterine NK cells: active regulators at the maternal-fetal interface. J. Clin. Invest 124(5): 1872-1879.

20. Wu Y, Tian Z, Wei H (2017) Developmental and Functional Control of Natural Killer Cells by Cytokines. Front Immunol 8: 930.

21. Sang L, Fang QJ, Zhao XB (2019) A research on the protein expression of p53, p16, and MDM2 in endometriosis. Medicine 98(14): e14776.

22. Otsuki Y (2016) ER $\alpha$ Signal pathways regulating Bcl-2 transcription in human endometrial glands. Kanzaki H (edt), Uterine Endometrial Function, Tokyo: Springer.

23. Melkozerova OA, Shchedrina ID, Mikhelson AA, Zyryanov MN, Panacheva NM (2019) The effectiveness of focused ultrasound ablation of uterine fibroids under the control of magnetic resonance imaging in patients of reproductive age with a symptomatic course of uterine fibroids. Russian Bulletin of the Obstetrician-Gynecologist 19 (5): 52-60. 